\title{
Surgical Management of Intestinal Tuberculosis in Preoperatively Unsuspected Cases at a Tertiary Care Hospital in Dhaka City
}

\author{
Mizanur Rahman 1,*, Abdullah Yusuf ${ }^{2}$, Mahfuzur Rahman², Meraj Uddin Mollah', \\ Shah Muhammad Aman Ullah ${ }^{4}$, Ayub Ali ${ }^{5}$ \\ ${ }^{1}$ Ortho-Surgery, Gafargaon Upazilla Health Complex, Mymensingh, Bangladesh \\ ${ }^{2}$ Department of Microbiology, National Institute of Neurosciences \& Hospital, Dhaka, Bangladesh \\ ${ }^{3}$ National Institute of Traumatology and Orthopaedic Rehabilitation, Dhaka, Bangladesh \\ ${ }^{4}$ National Institution of Burn \& Plastic Surgery, Dhaka Medical College Hospital, Dhaka, Bangladesh \\ ${ }^{5}$ Ortho-Surgery, Sadar General Hospital, Cox’s Bazar, Bangladesh \\ *Corresponding author: mizan2121@yahoo.com
}

\begin{abstract}
Background: Surgical management of intestinal tuberculosis is a crucial task in preoperatively unsuspected cases. Objective: The present study was undertaken to see the different surgical management of intestinal tuberculosis in preoperatively unsuspected cases. Methodology: This clinical trial was conducted in different units of the Department of Surgery at Dhaka Medical College Hospital, Dhaka from March 2002 to March 2004 for a period of two (2) years. Purposive sampling technique was applied to collect the study population. Patients with no suspicion about pulmonary as well as intestinal tuberculosis, history of cough \& hemoptysis, no history of antitubercular drug taken, diagnosed as other than tuberculosis, per operative suspicion raised by any one or more of followings, enlarge lymph nodes in mesentery, omental masses, ileocaecal masses, suspicious growth in ileum, omental thickening, perforation suspected by tuberculosis were selected as study population. Biopsy was taken from suspicious lesions. Histopathology was confirmed the granulomatous lesion. Results: A total number of 300 patients were undergone surgical intervention of which 38(12.7\%) cases. Maximum affected age group was 21 to 30 years which was $16(42 \%)$ cases. Granulomatous inflammation was found in 12(31.6\%) cases. Maximum mode of presentation was in the form of emergency which was 36(94.7\%) cases. Tissue was taken for biopsy from mesenteric lymph node in 16(42.10\%) cases. Procedures done during laparotomy were resection of ileum and ileoileal anastomosis and proximal ileostomy which was performed in 6(23.07\%) cases, resection of ileum and ileostomy in 5(19.23\%) cases and resection of ileum with ileoileal anastomosis in 3(11.53\%) cases. Conclusion: In conclusion surgical management is performed by resection of jejunum with jejunojejunal anastomosis, hemicolectomy with ileotrasverse anastomosis and resection of ileum with ileostomy.
\end{abstract}

Keywords: tuberculosis, unsuspected, laparotomy, surgical management

Cite This Article: Mizanur Rahman, Abdullah Yusuf, Mahfuzur Rahman, Meraj Uddin Mollah, Shah Muhammad Aman Ullah, and Ayub Ali, "Surgical Management of Intestinal Tuberculosis in Preoperatively Unsuspected Cases at a Tertiary Care Hospital in Dhaka City.” Global Journal of Surgery, vol. 5, no. 1 (2017): 11-13. doi: 10.12691/js-5-1-4.

\section{Introduction}

Tuberculosis occurs in different parts of the body of which abdomen is the sixth most common extra-pulmonary site affected by tuberculosis [1]. The portal of entry into the abdomen includes hematogenous spread, ingestion of infected sputum or infected milk and from adjacent organs [2]. In the abdomen, tuberculosis may affect the gastrointestinal tract, peritoneum, lymph nodes, and solid viscera. Intestinal tuberculosis exists as ulcerative, hypertrophic or stricture form. However, peritoneal involvement exists as ascitic, loculated, plastic and purulent forms [3].
There are several clinical presentation of intestinal tuberculosis and these may be presented with complications like acute or sub-acute intestinal obstruction due to mass or stricture formation or gut perforation leading to peritonitis [4]. The treatment of abdominal tuberculosis is mainly conservative with anti-tuberculous therapy and surgical treatment is reserved for complications [5]. Generally, surgical treatment which is followed by anti-tuberculosis drug treatment may give excellent results [6]. There are several surgical treatment modalities for the management of intestinal tuberculosis. Therefore, this present study was undertaken to see the different surgical management of intestinal tuberculosis in preoperatively unsuspected cases. 


\section{Methodology}

This clinical trial was conducted in different units of the Department of Surgery at Dhaka Medical College Hospital, Dhaka from March 2002 to March 2004 for a period of two (2) years. Purposive sampling was done according to availability of the patients and strictly considering the inclusion and exclusion criteria. Patients with no suspicion about pulmonary as well as intestinal tuberculosis, history of cough and haemoptysis, no history of anti-tubercular drug taken, diagnosed as other than tuberculosis, per operative suspicion raised by any one or more of followings, enlarge lymph nodes in mesentery, omental masses, ileocaecal masses, suspicious growth in ileum, omental thickening, perforation suspected by tuberculosis were selected as study population. The patients were undergone different surgical management. The surgical management was performed under emergency or elective surgery. These surgical management were perforation site exteriorize as stoma, stricturoplasty, resection of jejunum with jejunojejunal anastomosis, right hemicolectomy with ileotrasverse anastomosis, resection of ileum with ileostomy, resection of ileum with Ileo-ileal anastomosis as well as resection of ileum with ileoileal anastomosis and proximal loop ileostomy. Biopsy was taken from suspicious lesions of different organs. Histopathology was confirmed the granulomatous lesion. Patients with known case of tuberculosis, suspicion about pulmonary tuberculosis, history of cough and haemoptysis, previously treated with anti-tubercular drugs and chest X-ray with suspicion of pulmonary tuberculosis were excluded from this study. Statistical analysis was performed by Statistical Package for Social Science (SPSS version 20.0, USA). The quantitative variables were expressed as frequency and percentage. The qualitative data were compared with Chi-square test to see the level of significance. $\mathrm{P}$ value less than 0.05 was taken as statistically significance.

\section{Results}

A total number of 300 patients were undergone surgical intervention of which 38(12.7\%) cases. Maximum were found in 21 to 30 age group which was $70(23.3 \%)$ followed by 31-40 age group and below 20 years of age group which were 62(20.66\%) cases and 56(18.66\%) cases respectively. Maximum affected age group was 21 to 30 years which was $16(42 \%)$ cases (Table 1 ).

Table 1. Age distributions of among the Study Population $(n=300)$

\begin{tabular}{|c|c|c|c|}
\hline \multirow{2}{*}{ Age Group } & \multicolumn{2}{|c|}{ Intestinal Tuberculosis } & \multirow{2}{*}{ Total } \\
\hline & Present & Absent & \\
\hline Less than 20 Years & $8(14.3 \%)$ & $48(85.7 \%)$ & $56(100.0 \%)$ \\
\hline 21 to 30 Years & $16(22.8 \%)$ & $54(77.2 \%)$ & $70(100.0 \%)$ \\
\hline 31 to 40 Years & $8(12.9 \%)$ & $54(87.1 \%)$ & $62(100.0 \%)$ \\
\hline 41 to 50 Years & $6(11.5 \%)$ & $46(88.5 \%)$ & $52(100.0 \%)$ \\
\hline 51 to 60 Years & $0(0.0 \%)$ & $44(100.0 \%)$ & $44(100.0 \%)$ \\
\hline More than 60 Years & $0(0.0 \%)$ & $16(100.0 \%)$ & $16(100.0 \%)$ \\
\hline Total & $38(12.7 \%)$ & $262(87.3 \%)$ & $300(100.0 \%)$ \\
\hline
\end{tabular}

Maximum mode of presentation was in the form of emergency which was 36(94.7\%) cases and the rest 2(5.3\%) cases were presented as routine management (Table 2).

Tissue was taken for biopsy from mesenteric lymph node in $16(42.10 \%)$ cases; part of ileum was in 14(36.84\%) cases and jejunal wall was in 5(13.15\%) cases (Table 3).

Perforation site exteriorize as stoma was performed in $4(15.38 \%)$ cases. Stricturoplasty was done in $1(3.84 \%)$ case. Resection of jejunum with jejunojejunal anastomosis was performed in $4(15.38 \%$ ) cases. Right hemicolectomy with ileotrasverse anastomosis was done in $3(11.53 \%)$ cases. Resection of ileum with ileostomy was done in $5(19.23 \%)$ cases. Resection of ileum with ileo-ileal anastomosis was done in $3(11.53 \%)$ cases. Resection of ileum with ileoileal anastomosis and proximal loop ileostomy was done in 6(23.07\%) cases (Table 4).

Table 2. Nature of Presentation in emergency or routine cases $(n=38)$

\begin{tabular}{|l|c|c|}
\hline Nature of Presentation & Frequency & Percentage \\
\hline Emergency cases & 36 & 94.7 \\
\hline Routine cases & 2 & 5.3 \\
\hline Total & $\mathbf{3 8}$ & $\mathbf{1 0 0 . 0}$ \\
\hline
\end{tabular}

Table 3. Distribution of tissue taken for histopathology in Positive cases $(\mathbf{n}=38)$

\begin{tabular}{|l|c|c|}
\hline Sites of Tissue & Frequency & Percentage \\
\hline Mesenteric Lymph nodes & 16 & 42.1 \\
\hline Part of ileum & 14 & 36.8 \\
\hline Caecal wall & 3 & 7.9 \\
\hline Jejunal wall & 5 & 13.1 \\
\hline Total & 38 & 100.0 \\
\hline
\end{tabular}

Table 4. Distribution of Patient by the Type of Operation $(\mathrm{N}=38)$

\begin{tabular}{|l|c|c|}
\hline Name of Operation & Frequency & Percentage \\
\hline Perforation site exteriorize as stoma & 4 & 15.38 \\
\hline Stricturoplasty & 1 & 3.84 \\
\hline $\begin{array}{l}\text { Resection of jejunum \& jejunojejunal } \\
\text { anastomosis }\end{array}$ & 4 & 15.38 \\
\hline $\begin{array}{l}\text { Right hemicolectomy \& ileotrasverse } \\
\text { anastomosis }\end{array}$ & 3 & 11.53 \\
\hline Resection of ileum \& ileostomy & 3 & 11.53 \\
\hline $\begin{array}{l}\text { Resection of ileum \& Ileo-ileal } \\
\text { anastomosis }\end{array}$ & 6 & 23.07 \\
\hline $\begin{array}{l}\text { Resection of ileum \& ileoileal } \\
\text { anastomosis \& proximal loop } \\
\text { ileostomy }\end{array}$ & & \\
\hline
\end{tabular}

\section{Discussion}

Abdominal tuberculosis affects all parts of abdomen including intestine, peritoneum, lymph nodes and solid organs [7]. Because of its non-specific nature, a wide variety of presentation and ability to mimic other abdominal diseases, a high index of suspicion is needed [8]. The disease remains undiagnosed, misdiagnosed or delayed diagnosed till patient develops complications such as intestinal obstruction or perforation peritonitis. 
The accuracy of clinical acumen is less than half percentage [6]. No reliable investigation, except histopathology, can diagnose this disease. Abdominal tuberculosis predominantly involves the younger age population as evident with third decade being the most commonly affected. This correlates well with other national and international studies [7-12].

Parts of the body involved by tuberculosis are mesenteric lymph node, ileum, caecal wall and jejunal wall. In this current study, involved parts of the body as lymphadenopathy is $42.1 \%$ which is correlate with the study of Sinan et al [8] which is $46.9 \%$, in the current study bowel wall involvement is $57.9 \%$ which is higher than that of study of Sinan et al [8] which is 38\% cases.

In this study nature of presentation in positive cases are emergency cases 36 in number and percentage is $94.73 \%$; routine cases only 2 in number and percentage is $5.27 \%$. In this study large numbers of patients are in low socio-economic group, majority of them are unaware and neglect their initial symptoms and urge treatment when the disease becomes complicated. Detail preoperative investigations are not possible before emergency operations.

There are variations of the surgical treatment according to the involvement of the intestine. Perforation site exteriorize as stoma was performed in $4(15.38 \%)$ cases. Stricturoplasty was done in $1(3.84 \%)$ case. Resection of jejunum with jejunojejunal anastomosis was performed in 4(15.38\%) cases. Right hemicolectomy with ileotrasverse anastomosis was done in $3(11.53 \%)$ cases. Resection of ileum with ileostomy was done in 5(19.23\%) cases. Resection of ileum with ileo-ileal anastomosis was done in 3(11.53\%) cases. Resection of ileum with ileoileal anastomosis and proximal loop ileostomy was done in 6(23.07\%) cases. All of those eases are late cases and are operated as the complication of tuberculosis. These are the plan of treatment though the definitive treatment of tuberculosis is the chemotherapy $[13,14,15]$ which has been given in every patient.

Newer modalities of diagnostic aids like laparoscopy, CT scan of the abdomen can be helpful for easy diagnosis but it is still impossible in the context of our socioeconomic condition. Currently developed serological methods and ascitic fluids study helps early diagnosis of the enteric tuberculosis. Early diagnosis is very much essential to avoid unnecessary operation. A full course of anti tubercular therapy is the primary treatment of tuberculosis. Surgery should be reserved for the complications.

\section{Conclusion}

In conclusion maximum modes of presentation are emergency cases and surgical management is performed by resection of jejunum with jejunojejunal anastomosis, hemicolectomy with ileotrasverse anastomosis and resection of ileum with ileostomy. Mesenteric lymph node is the most common detection site of intestinal tuberculosis. Patients presented with surgical emergency should be ruled out to see the presence of intestinal tuberculosis.

\section{References}

[1] Kapoor VK. Abdominal tuberculosis: The Indian contribution. Indian J Gastroenterol 1998; 17: 141-17.

[2] Shah SM, Hafeez MA, Khan N, Khan M, Shah SM, Bangash A. Surgical Management of Intestinal Tuberculosis. Journal of Postgraduate Medical Institute (Peshawar-Pakistan). 2011; 20(4): 379-84.

[3] Pulimood AB, Amarapurkar DN, Ghoshal U, Phillip M, Pai CG, Reddy DN, Nagi B, Ramakrishna BS. Differentiation of Crohn's disease from intestinal tuberculosis in India in 2010. World J Gastroenterol. 2011; 17(4): 433-43.

[4] Abro A, Siddiqui FG, Akhtar S, Memon AS. Spectrum of clinica presentation and surgical management of intestinal tuberculosis at tertiary care hospital. J Ayub Med Coll Abbottabad. 2010; 22(3): 96-9.

[5] Mukewar S, Mukewar S, Ravi R, Prasad A, Dua KS. Colon tuberculosis: endoscopic features and prospective endoscopic follow-up after anti-tuberculosis treatment. Clinical and translational gastroenterology. 2012; 3(10): e24.

[6] Lee WK, Van Tonder F, Tartaglia CJ, Dagia C, Cazzato RL, Duddalwar VA, Chang SD. CT appearances of abdominal tuberculosis. Clinical radiology. 2012; 67(6): 596-604.

[7] Guirat A, Koubaa M, Mzali R, Abid B, Ellouz S, Affes N, Jemaa MB, Frikha F, Amar MB, Beyrouti MI. Peritoneal tuberculosis. Clinics and research in hepatology and gastroenterology. 2011; 35(1): 60-9.

[8] Sinan T, Sheikh M, Ramadan S, Sahwney S, Behbehani A. CT features in abdominal tuberculosis: 20 years experience. BMC medical imaging. 2002;2(1):3.

[9] National Guideline and operational Manual for tuberculosis Control, 3rd, July 2004.

[10] Puri R, Mangla R, Eloubeidi M, Vilmann P, Thandassery R, Sud R. Diagnostic yield of EUS-guided FNA and cytology in suspected tubercular intra-abdominal lymphadenopathy. Gastrointestinal endoscopy. 2012; 75(5): 1005-10.

[11] Ulusoy AN, Karabicak I, Dicle K, Kefeli M, Tosun M, Cetinkaya M, Alper T, Ustun C. Peritoneal tuberculosis in premenopausa patients with elevated serum CA 125 . Archives of gynecology and obstetrics. 2010; 282(6): 639-42.

[12] Choudhury MR. Modern medical microbiology. $3^{\text {rd }}$ ed. Bishwa Parichaya; 1999.

[13] Tuberculosis in Bangladesh, Annual report: 2003 National tuberculosis control program, Directorate General of Health Services, Mohakhali, Dhaka.

[14] Management of the opportunist mycobacteria infection: Join Tuberculosis Committee Guideline 1999.

[15] Roui HMA. Problem of the intestinal tuberculosis in Bangladesh: Case study and review, [Dissertation Surgery]. Bangladesh College of Physician and Surgeon, 2012. 